Research article

\title{
Preliminary behavioral assessment of cagemates living with conspecifics submitted to chronic restraint stress in mice
}

\author{
P.E. Carneiro de Oliveira ${ }^{\mathrm{a}}$, Caroline R. Zaniboni ${ }^{\mathrm{a}, \mathrm{b}}$, Isabela M. Carmona ${ }^{\mathrm{a}, \mathrm{b}}$, \\ Aura R. Fonseca ${ }^{a, c}$, Azair Canto-de-Souza ${ }^{a, b, c, d, *}$ \\ a Department of Psychology, Psychobiology Group/UFSCar, São Carlos, SP, Brazil \\ b Graduate Program in Psychology/UFSCar, São Carlos, SP, Brazil \\ c Joint Graduate Program in Physiological Sciences UFSCar/UNESP, Araraquara, SP, Brazil \\ ${ }^{\mathrm{d}}$ Neuroscience and Behavioral Institute, Ribeirão Preto, SP, Brazil
}

\section{H I G H L I G H T S}

- Anxiogenic-like behaviors and hypernociception observed in the cagemates of mice submitted to chronic restraint stress.

- Cagemate living with mice in repeated stress condition promotes alterations in defensive behaviors in rat exposure test.

- Behavioral alterations were observed in both stressed mice and their cagemates.

- Anxiogenic-like behaviors and hypernociception observed in the cagemates of mice submitted to chronic restraint stress.

- Cagemate living with mice in repeated stress condition promotes alterations in defensive behaviors in rat exposure test.

- Behavioral alterations were observed in both stressed mice and their cagemates.

\section{A R T I C L E I N F O}

\section{Article history:}

Received 3 March 2017

Received in revised form 24 June 2017

Accepted 5 July 2017

Available online 15 July 2017

\section{Keywords:}

Chronic restraint stress

Emotional contagion

Anxiety

Nociception

Rat exposure test

Mice

\begin{abstract}
A B S T R A C T
The capacity of rodents to recognize and respond to emotional signs from a conspecific is a valuable adaptive behavior, which provides essential skills for species survival. However, repeated exposure to aversive situations may elicit maladaptive behavioral responses in subjects that experience noxious episodes and their colony members. Previous findings by our group demonstrated that living with a subject in neuropathic pain induces anxiogenic-like behaviors and hypernociception in mice. Whereas chronic pain may be considered a stressful stimulus, we extended our findings on stress-induced emotional transfer. For this purpose, we investigated whether cohabitation with a partner subjected to chronic restraint stress was able to promote alterations in anxiety-like behaviors, pain sensibility and defensive responses. Male Swiss mice were housed in pairs for 14 days and then separated into control, stress, and cagemate groups. The stress group was subjected to 14 days of restraint stress $(1 \mathrm{~h} /$ day $)$ in the presence of the cagemates, while the pair-housed control group was left undisturbed. A day after last stress session control, stress, and cagemate groups were evaluated using elevated plus maze test, writhing test, and rat exposure test. Results demonstrated that chronic stress attenuated weight gain in the stress group. Moreover, cohabitation with mice subjected to chronic restraint stress induced anxiogenic-like behaviors, pain hypernociception, and alterations in defensive responses in both cagemate and stress groups. These preliminary findings suggest that chronic exposure to aversive stimulus may induce behavioral alterations even in observers.
\end{abstract}

(c) 2017 Published by Elsevier Ireland Ltd.
* Corresponding author at: Department of Psychology, Psychobiology Group/CECH UFSCar, Rod Washington Luís, Km 235, 13565 905, Sã Carlos, SP, Brazil

E-mail addresses: souzaalm@ufscar.br, souzaalm@gmail.com

(A. Canto-de-Souza)

\section{Introduction}

In rodents, the ability to recognize and respond when conspecifics are exposed to negative events is a valuable adaptive behavior. This social learning signifies interactions among behavioral, cognitive and emotional processes that provide essential skills for the species survival [1-3]. Conversely, although social observation improves defensive strategies toward potential threats 
[4], it has been reported that repeated exposure to aversive situations may elicit maladaptive behavioral responses in subjects that experience noxious episodes and their colony members $[5,6]$. In this sense, laboratory approaches have used pain models to study the behavioral consequences of chronic distress situations. For instance, studies have shown abnormal anxiety behaviors and pain sensitivity in rodents subjected to chronic sciatic nerve constriction (neuropathic pain model) [5,7-11]. Likewise, studies conducted by our group demonstrated that the cagemates of animals experiencing chronic pain also exhibited anxiogenic-like behaviors on the elevated plus maze and hyperalgesia on the writhing test $[6,12,13]$.

Thus, given that chronic neuropathic pain may be considered a stressful stimulus [14,15] and that stress promotes [16-18] anxiety-related responses and hypernociception, we propose a new protocol for studying stress-induced emotional contagion.

We investigated the effects of cohabitation on nociception, anxiety, and defensive behavior in cagemates of mice subjected to repeated restraint stress. For the assessment of defensive behavior, we used the rat exposure test. In contrast to the elevated plus maze, which exclusively examines anxiety behavior, the rat exposure test is a model of fear/anxiety that allows the mouse to regulate its own exposure by approaching or avoiding the predatory stimulus $[19,20]$. Exposure to a predatory threat elicits a natural unconditioned fear response, capable of inducing a set of intense physiological and behavioral defensive responses in the prey [19-22]. Several studies have shown that chronic stress exposure leads to impaired conditioned fear responses, such as excessive fear acquisition and delayed fear extinction [23-25]. However, no study has examined the effect of repeated stress on fear/anxiety responses in mice subjected to the rat exposure test.

In this paper we propose a protocol for studying the behavioral consequences of cohabitating with a conspecific subjected to chronic restraint stress. For this purpose, we assessed three different behaviors: anxiety-like behavior on the elevated plus maze, pain sensitivity, and defensive responses in both stressed mice and their cagemates.

\section{Methods}

\subsection{Subjects}

Male Swiss mice (18-20g) obtained from the animal breeding facility of the Federal University of São Carlos, São Paulo, Brazil, were moved to the laboratory animal facility of the Psychobiology Group and housed two per cage [ $19 \mathrm{~cm}$ (width) $\times 30 \mathrm{~cm}$ (length) $\times 14 \mathrm{~cm}$ (height)]. Mice were consistently maintained on a regular light-dark cycle $(12 \mathrm{~h} / 12 \mathrm{~h}$, lights on at 7:00 a.m.) under controlled temperature $\left(23^{\circ} \mathrm{C}\right)$, with unrestricted access to food and water. The four male Long-Evans rats $(450-600 \mathrm{~g})$ used in the rat exposure test were kept in a separated room in the same conditions. All experiments were performed during the light phase. The experimental procedures were in compliance with the recommended protocol approved by the Brazilian Guidelines for Care and Use of Animals for Scientific and Educational Purposes, elaborated by The National Council of Control of Animal Testing (CONCEA). This study was approved by the Ethics Committee on Animal Experiments (CEUA 4996150816).

\subsection{General procedure}

On the twenty-first day after birth (weaning), 110 mice were housed in pairs for 14 days and left undisturbed (first to fourteenth day), except for cage cleaning. After this period, the mice were separated into control group and stress and cagemate groups. The mice in the stress group were placed inside a pipe once a day for $1 \mathrm{~h}$ for 14 additional days inside the homecage placed in an adjacent room, while their cagemates remained inside the same homecage, observing the stress session. The control group pairs were moved to another adjacent room and left undisturbed for $1 \mathrm{~h}$. After each stress session, all animals were weighted and then returned to the animal facility (fifteenth to twenty-eighth day). A day after the last stress session (twenty-ninth day) mice from the control, cagemate, and stress groups were subjected to different behavioral tests. Each animal underwent only one behavioral test (Fig. 1). All procedures (stress sessions and tests) were run during light cycle and the observers, who scored the behavioral tests, were blinded to the chronic conditions of the subjects.

\subsection{Restraint stress}

Chronic restraint stress was performed using a PVC pipe $[14 \mathrm{~cm}$ (length) $\times 3 \mathrm{~cm}$ (diameter)]. The animals of the stress group were placed inside the pipe once a day for $1 \mathrm{~h}$ for 14 days in the presence of their cagemates, in the homecage that was moved to an adjacent room. The control group pairs were moved to another adjacent room once a day for $1 \mathrm{~h}$ during the 14 days of stress sessions.

\subsection{Body weight gain}

All subjects in the control, cagemate, and stress groups were weighted every day during the 14 days of stress sessions after the intervention. Weight gain was calculated based on the equation [(weight on fourteenth day) - (weight on first day)].

\subsection{Elevated plus maze test (EPM)}

Anxiety-like behavior was assessed by the EPM test. The elevated plus maze used was similar to that described by Lister [26] and consisted of a wooden maze coated by plastic laminate, raised $38.5 \mathrm{~cm}$ from the floor, with four arms arranged in a plus format with two opposite arms closed by transparent glass walls $(30 \times 5 \times 15 \mathrm{~cm})$, connected by a common central platform $(5 \times 5 \mathrm{~cm})$ with two opposite open arms $(30 \times 5 \times 0.25 \mathrm{~cm})$. All tests were conducted during the light phase of the light-dark cycle, under the illumination of 77 lux on the floor of the apparatus [6]. Animals were placed in the center of the maze facing an open arm. The number of entries and time spent in each arm were recorded for $5 \mathrm{~min}$. An entry was considered when the animal put all feet in any arm. Conventional measures were the percentage of open arm entries [(open/total entries $) \times 100]$ and the percentage of time spent in open arms [(open/total time) $\times 100]$. These activities have been used as an index of anxiety behavior [26,27]. The number of closed arm entries was used to measure locomotor activity in mice. Complementary behaviors measured were the percentage of time spent in the central plataform [(central/total time $) \times 100]$, the number of head-dippings (exploratory movement of head/shoulders over sides of the maze), the percentage of protected head-dipping [(protected/total) $\times 100$ ], the number of stretch attend postures (SAP; an exploratory posture in which the mouse stretches forward and retracts to original position without locomotion), and the percentage of protected SAP [(protected/total $) \times 100]$. Behaviors such as head-dipping and stretched attend postures were used to measure risk assessment [27]. In addition, depending on where these behaviors were exhibited, they were counted as protected or unprotected. In line with previous studies, the closed arms and central platform were together designated as protected areas of the maze, while the open arms were designated as unprotected areas [27,28]. Between tests, the apparatus was cleaned with ethanol $20 \%$ and dried with a cloth. All sessions were recorded by a vertically mounted camera linked to a computer for posterior analysis. Test videos were scored by a highly trained observer using the free software $\mathrm{X}$ - 


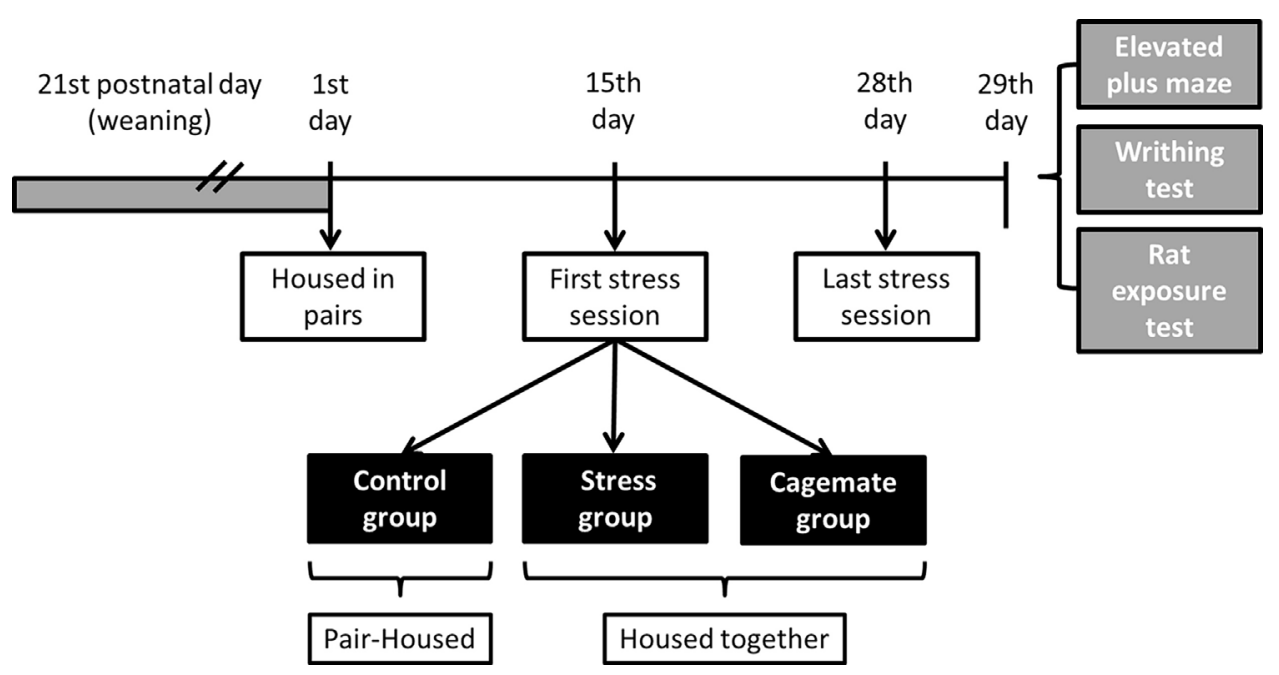

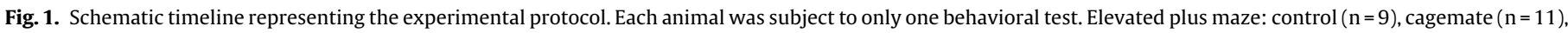
and stress $(n=11)$; Writhing test: control $(n=11)$, cagemate $(n=12)$, and stress $(n=12)$; Rat exposure test: control $(n=15)$, cagemate $(n=14)$, and stress $(n=14)$.

PloRat, developed at the Laboratory of Exploratory Behavior, São Paulo University, Ribeirão Preto, Brazil.

\subsection{Nociception test}

Pain sensitivity was assessed by the writhing test, as described by Collier et al. [29]. Writhes were induced by intraperitoneal injection of acetic acid $0.6 \%(10 \mathrm{~mL} / \mathrm{Kg}) 5 \mathrm{~min}$ before the beginning of the test. Injection of an irritant substance in the peritoneal cavity evokes a characteristic response consisting of wave constriction and elongation of the abdomen, accompanied by hyperextension of the hind limbs and arching of the back. Mice were individually tested in a non homecage plastic box covered with sawdust, and the number of writhes was measured for $5 \mathrm{~min}$.

\subsection{Rat exposure test (RET)}

The rat exposure test, described by Yang et al. [20], comprised a clear polycarbonate exposure chamber $(23 \times 24 \times 21 \mathrm{~cm})$ covered with a black polycarbonate lid and joined to a burrow chamber $(7 \times 7 \times 12 \mathrm{~cm})$ by a transparent Plexiglas tube tunnel $(4.4 \mathrm{~cm}$ in diameter and $13 \mathrm{~cm}$ in length). A wire mesh screen divided the exposure chamber into two equal-sized compartments (the surface and the predator compartment). All tests were conducted during the light phase of the light-dark cycle, under the illumination of 20 lux on the floor of the apparatus. Animals were put on the burrow chamber and allowed to freely explore the apparatus for $5 \mathrm{~min}$ in the presence of a Long-Evans rat. Conventional measures were time spent in the burrow chamber, time spent in the tunnel, time spent in the protected area (burrow + tunnel), the latency of first exit from the protected area, time spent in the unprotected area (surface), frequency of rearings, crossings between protected and unprotected areas, time of defensive burying (digging and/or pushing of the sawdust), total freezing time (protected + unprotected areas), and percentage of protected freezing [(protected freezing/total freezing) $\times 100$ ]. Complementary behaviors measured were the total time in stretch attend posture, burrow SAP, tunnel SAP, protected SAP (burrow SAP + tunnel SAP), and percentage of unprotected SAP [(surface SAP/total SAP) $\times 100]$. Protected area behaviors were considered when the mice exhibited responses with at least the hind limbs inside the burrow or tunnel. Unprotected area behaviors were considered when the mice exhibited responses with all four limbs outside the burrow or tunnel [20]. Between tests, the apparatus was cleaned with ethanol $20 \%$ and dried with a cloth. All sessions
Table 1

Body weight gain during 14 days of restraint stress.

\begin{tabular}{llll}
\hline Group & \multicolumn{2}{l}{ Stress day } & \\
\cline { 2 - 4 } & 1 st & 14 th & weight gain $(\mathrm{g})$ \\
\hline Control & $39.49 \pm 0.62$ & $47.22 \pm 0.72$ & $7.72 \pm 0.31$ \\
Stress & $38.76 \pm 0.79$ & $41.58 \pm 0.72$ & $2.82 \pm 0.37^{\mathrm{a}}$ \\
Cagemate & $38.16 \pm 0.86$ & $45.32 \pm 1.04$ & $7.17 \pm 0.46$ \\
\hline
\end{tabular}

Data are presented as mean \pm s.e.m.

${ }^{a} \mathrm{p}<0.001$ vs. control and cagemate groups.

were recorded by a vertically mounted camera linked to a computer for posterior analysis.Test videos were scored by a highly trained observer using the free software X-PloRat, developed at the Laboratory of Exploratory Behavior, São Paulo University, Ribeirão Preto, Brazil.

\subsection{Statistical analysis}

All collected data were expressed as means \pm SEM. Normally distributed data were analyzed by one-way ANOVA followed by Newman-Keuls post-hoc test comparing the three groups: control, cagemate, and stress. For nonparametric data, Kruskal-Wallis test were used for multiple comparisons. Results of statistical tests with $\mathrm{p}<0.05$ were considered significant.

\section{Results}

\subsection{Body weight gain during 14 days of restraint stress.}

Table 1 presents the data of weight gain measured during the 14 days of stress sessions. The statistical analysis showed that chronic restraint stress attenuated weight gain only in the stress group during the14 days, compared to the control and cagemate groups $\left[\mathrm{F}_{(2,106)}=48.40 ; \mathrm{p}<0.0001\right]$.

\subsection{Anxiogenic-like behavior in the cagemates of mice submitted to chronic restraint stress.}

Fig. 2A depicts behavioral responses of mice tested on the elevated plus maze. Data is shown as mean + SEM for the control $(n=9)$, cagemate $(n=11)$ and stress $(n=11)$ groups. The statistical analysis showed a decrease in the percentage of open arm entries $\left[F_{(2,28)}=13.15 ; \mathrm{p}<0.0001\right]$ and the percentage of time spent in open 
(A)

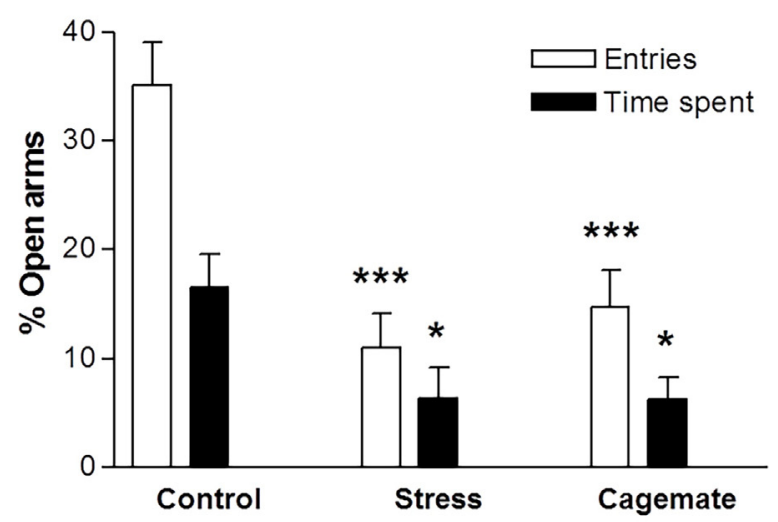

(B)

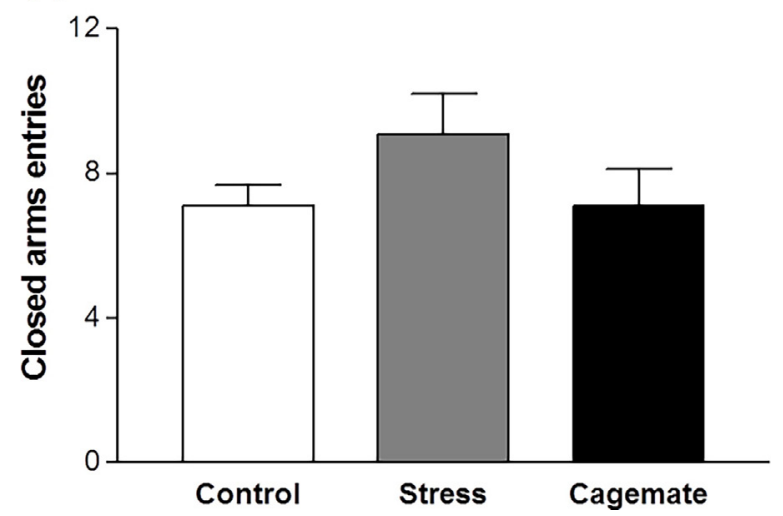

Fig. 2. Effects of chronic restraint stress on anxiety-like behaviors represented as (A) percentage of time spent and entries in open arms in the elevated plus maze and (B) number of closed arms entries. Data are presented as mean \pm SEM. ${ }^{*} \mathrm{p}<0.05$ vs. control group; ${ }^{* * *} \mathrm{p}<0.001$ vs. control group.

Table 2

Anxiety-like behaviors after 14 days of restraint stress.

\begin{tabular}{llll}
\hline Behavior & Control & Stress & Cagemate \\
\hline center time (\%) & $43.02 \pm 4.04$ & $32.83 \pm 3.10$ & $33.51 \pm 3.25$ \\
head-dipping (frequency) & $21.11 \pm 2.65$ & $23.64 \pm 1.30$ & $17.55 \pm 1.59$ \\
protected head-dipping (\%) & $82.15 \pm 4.62$ & $96.41 \pm 1.81^{* *}$ & $95.60 \pm 2.26^{* *}$ \\
SAP (frequency) & $24.78 \pm 4.45$ & $22.91 \pm 3.05$ & $26.82 \pm 5.31$ \\
protected SAP (\%) & $72.98 \pm 3.63$ & $94.61 \pm 1.57^{* * *}$ & $94.38 \pm 2.34^{* * *}$ \\
\hline
\end{tabular}

Data are presented as mean \pm s.e.m.

${ }^{* *} \mathrm{p}<0.01$ vs. control group.

**** $\mathrm{p}<0.001$ vs. control group.

$\operatorname{arms}\left[\mathrm{F}_{(2,28)}=4.88 ; \mathrm{p}<0.05\right]$ in the cagemate and stress groups compared to the control group, indicating an anxiogenic-like effect induced by chronic restraint in both groups. Chronic stress did not modify the number of closed arm entries $\left[\mathrm{F}_{(2,28)}=1.41 ; \mathrm{p}=0.26\right]$ (Fig. 2B), suggesting there was no locomotor activity impairment in any group. Table 2 summarizes complementary anxiety-like behaviors assessed by the elevated plus maze test. The statistical analysis revealed an increase in the percentage of protected headdipping $\left[\mathrm{F}_{(2,28)}=7.00 ; \mathrm{p}<0.005\right]$ and protected $\mathrm{SAP}\left[\mathrm{F}_{(2,28)}=22.71\right.$; $\mathrm{p}<0.0001]$ in the cagemate and stress groups, but not in total headdipping $\left[\mathrm{F}_{(2,28)}=2.96 ; \mathrm{p}=0.07\right]$, total $\operatorname{SAP}\left[\mathrm{F}_{(2,28)}=0.21 ; \mathrm{p}=0.81\right]$, and percentage of time spent in the center platform $\left[\mathrm{F}_{(2,28)}=2.57\right.$; $\mathrm{p}=0.10]$. These behaviors confirm that chronic restraint stress produces anxiogenic-like behaviors in both stressed mice and their cagemates.

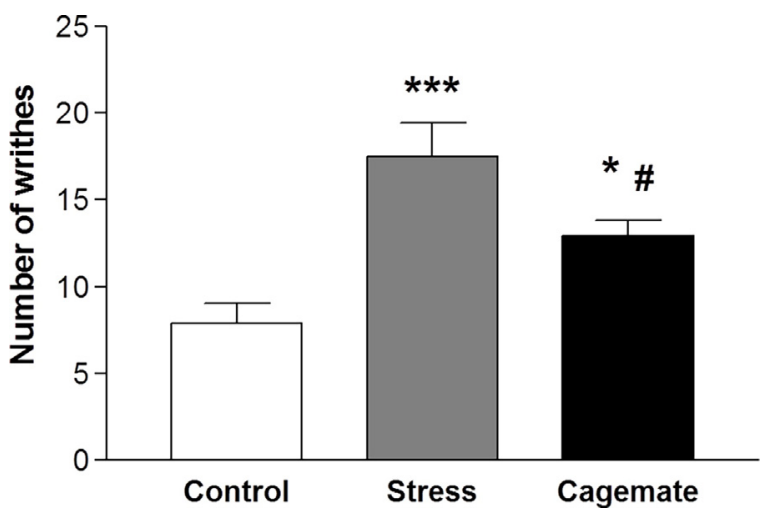

Fig. 3. Effects of chronic restraint stress on nociception represented as number of writhes. Data are presented as mean \pm SEM. ${ }^{*} \mathrm{p}<0.05$ vs. control group; ${ }^{* * *} \mathrm{p}<0.001$ vs. control group; \#p<0.05 vs. stress group.

\subsection{Hypernociception in the cagemates of mice submitted to chronic restraint stress}

Fig. 3 shows the number of writhes in the control $(n=11)$, cagemate $(n=12)$, and stress $(n=12)$ groups after intraperitoneal injection of acetic acid $0.6 \%$. One-way ANOVA followed by Newman-Keuls post-hoc test revealed that the stress and cagemate groups experienced more writhes compared to the control group. Conversely, cagemates cohabitating with the stress group for 14 days exhibited less number of writhes compared to the stressed animals $\left[\mathrm{F}_{(2,32)}=11.22 ; \mathrm{p}<0.0005\right]$. These results indicate that although the stress protocol induced hypernociception in both the stress and cagemate groups, it was highest in the stress group.

\subsection{Alterations of defensive responses in cagemates living with mice submitted to chronic restraint stress.}

Fig. 4 depicts the behavioral responses of mice tested on the rat exposure test. Data is show as mean + SEM for the control $(n=15)$, cagemate $(n=14)$, and stress $(n=14)$ groups. One-way ANOVA, followed by Newman-Keuls post-hoc test and Kruskal-Wallis test indicated that stressed animals and their cagemates exhibited alterations in defensive behaviors. Fourteen days of restraint stress decreased the time spent in the burrow chamber $\left[\mathrm{F}_{(2,40)}=5.16\right.$; $\mathrm{p}<0.05]$ (A) and time spent in the protected area $\left[\mathrm{H}_{(2,43)}=8.38\right.$; $\mathrm{p}<0.05](\mathrm{C})$, but not the time spent in the tunnel $\left[\mathrm{F}_{(2,40)}=0.82\right.$; $\mathrm{p}=0.45]$ (B). Furthermore, the latency of first exit from the protected area was decreased for these mice $\left[\mathrm{F}_{(2,40)}=5.67 ; \mathrm{p}<0.01\right]$ (D); they spent more time in the unprotected area $\left[\mathrm{H}_{(2,43)}=7.06\right.$; $\mathrm{p}<0.05]$ (E) and spent less time in defensive burying $\left[\mathrm{F}_{(2,40)}=7.41\right.$; $\mathrm{p}<0.005]$ (F). Table 3 shows that chronic restraint stress decreased burrow SAP $\left[\mathrm{F}_{(2,40)}=13.94 ; \mathrm{p}<0.0001\right]$ and increased the percentage of unprotected SAP $\left[\mathrm{F}_{(2,40)}=4.26 ; \mathrm{p}<0.05\right]$. These behaviors confirmed the alterations in risk assessment and exploratory behaviors in the stress and cagemate groups. The statistical analysis did not reveal differences in the frequency of crossings $\left[\mathrm{F}_{(2,40)}=2.67 ; \mathrm{p}=0.08\right]$, total freezing $\left[\mathrm{H}_{(2,43)}=1.71 ; \mathrm{p}=0.43\right]$, percentage of protected freezing $\left[\mathrm{F}_{(2,40)}=0.34 ; \mathrm{p}=0.71\right]$, tunnel SAP $\left[\mathrm{F}_{(2,40)}=0.49 ; \mathrm{p}=0.62\right]$, protected SAP $\left[\mathrm{F}_{(2,40)}=2.12 ; \mathrm{p}=0.13\right]$, total $\operatorname{SAP}\left[\mathrm{F}_{(2,40)}=3.14 ; \mathrm{p}=0.06\right]$, and rearing $\left[\mathrm{H}_{(2,43)}=1.14 ; \mathrm{p}=0.57\right]$. The lack of difference in total freezing and the percentage of protected freezing indicates that chronic restraint stress did not affect fearrelated behaviors in the stress and cagemate groups. 
(A)

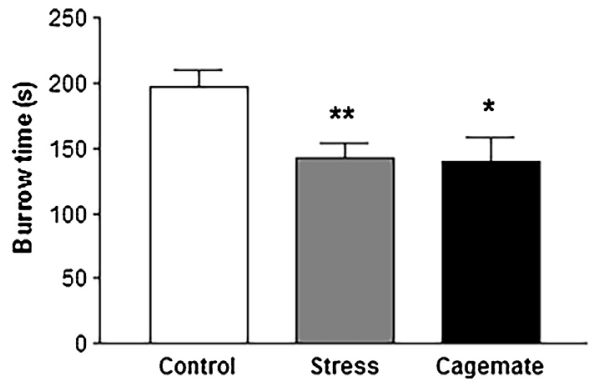

(C)

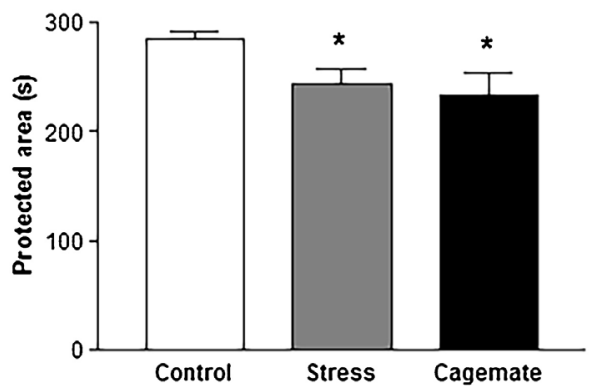

(E)

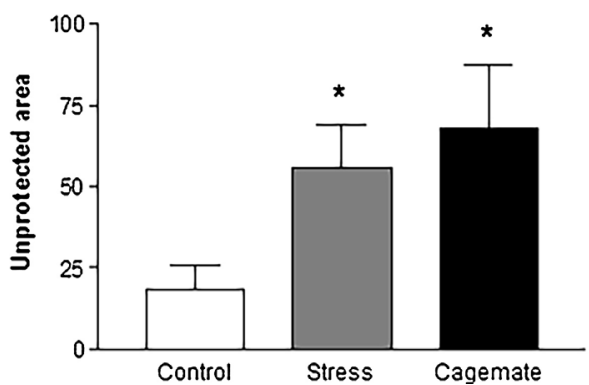

(B)

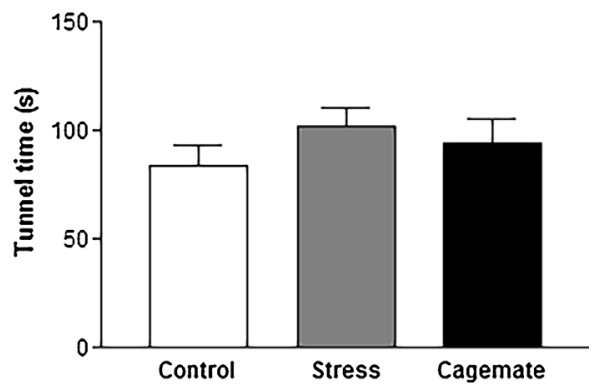

(D)

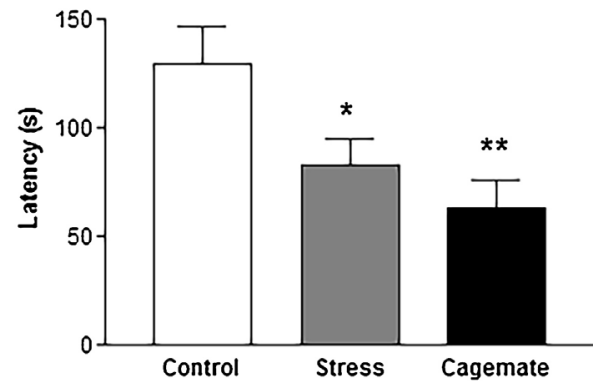

(F)

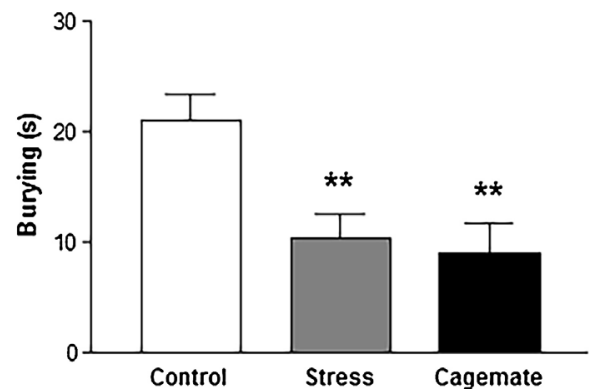

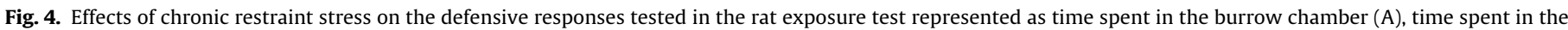

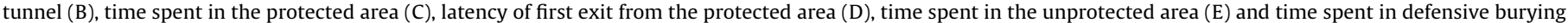
(F). Data are presented as mean \pm SEM. ${ }^{*} \mathrm{p}<0.05$ vs. control group; ${ }^{* *} \mathrm{p}<0.01$ vs. control group.

Table 3

Defensive responses after 14 days of restraint stress.

\begin{tabular}{|c|c|c|c|}
\hline Behavior & Control & Stress & Cagemate \\
\hline crossing prot/unprot areas (frequency) & $16.93 \pm 2.40$ & $25.50 \pm 3.52$ & $27.79 \pm 4.52$ \\
\hline total freezing $(\mathrm{s})$ & $11.39 \pm 2.59$ & $5.34 \pm 1.22$ & $8.43 \pm 2.72$ \\
\hline protected freezing (\%) & $88.44 \pm 7.29$ & $80.44 \pm 6.36$ & $81.43 \pm 8.79$ \\
\hline burrow SAP (s) & $48.46 \pm 3.30$ & $32.84 \pm 2.92^{* *}$ & $23.34 \pm 3.99^{* * * *}$ \\
\hline tunnel SAP $(\mathrm{s})$ & $54.26 \pm 6.97$ & $64.26 \pm 4.60$ & $55.24 \pm 9.15$ \\
\hline protected SAP (s) & $109.89 \pm 7.48$ & $123.62 \pm 5.40$ & $99.74 \pm 10.72$ \\
\hline total SAP $(\mathrm{s})$ & $117.39 \pm 8.79$ & $147.55 \pm 8.73$ & $117.16 \pm 11.73$ \\
\hline unprotected SAP (\%) & $5.47 \pm 1.93$ & $14.72 \pm 2.76^{*}$ & $14.88 \pm 3.17^{*}$ \\
\hline rearing (frequency) & $1.47 \pm 0.65$ & $5.87 \pm 2.57$ & $11.07 \pm 4.84$ \\
\hline
\end{tabular}

Data are presented as mean \pm s.e.m.

${ }^{*} \mathrm{p}<0.05$ vs. control group.

** $\mathrm{p}<0.01$ vs. control group.

${ }^{* * *} \mathrm{p}<0.001$ vs. control group. 


\section{Discussion}

The present study described a protocol to evaluate the behavioral consequences of cohabitation with mice exposed to chronic restraint stress. In this paper, we assessed anxiety-related behaviors, pain sensitivity, and unconditioned defensive responses. First, we found that chronic stress attenuated weight gain in the stress group. Furthermore, our results showed that stressed mice and their cagemates displayed anxiogenic-like behaviors in the elevated plus maze test, hypernociception evaluated by the writhing test, and alterations in defensive behavior in the rat exposure test.

Alterations in weight gain are a useful tool to indicate that a stress protocol has physiological effects [30-32]. Our data are in line with this idea as chronic restraint stress attenuated weight gain in the stress group as compared to the cagemate and control groups. Several studies have indicated that repeated restraint [30-34] and chronic unpredictable stress [35,36] attenuates body weight gain in both mice and rats. Conversely, the cagemates of stressed mice have no alterations in weight gain compared to control group. This finding indicates that chronic restraint stress may have different effects on weight gain for the stress and cagemate groups. Moreover, some studies have found no difference in body weight gain in rats after chronic restraint [35] and unpredictable stress [33]. Although, we found reduced weight gain in stress group the behavioral responses in all tests were very similar to cagemate group. These results indicate that decreased weight gain did not interfere in behavioral responses. Thus, our data suggest that stressinduced alterations in weight gain depend on factors such as the type, period, and relative intensity of stress exposure.

Besides weight gain determination, measurement of plasma corticosterone is often used to confirm whether a stress protocol is working. Although, we did not measure corticosterone levels in this study, chronic restraint is well known stress model. For instance, several published works that used chronic restraint stress did not measured corticosterone and observed behavioral alterations [37-40]. Furthermore, some studies have shown no difference in plasma corticosterone after chronic restraint [33,35]. Likewise, evidences from our group did not observed alterations in plasma corticosterone in cagemates cohabitating with mice submitted to chronic sciatic nerve constriction [6].

Chronically stressed mice and their cagemates exhibited anxiogenic-like behaviors, such as a decrease in the percentage of entries and time spent in open arms in the elevated plus maze. The effect of restraint stress on elevated plus maze responses is widely known and corroborates our findings. Some studies have shown that 14 days ( $2 \mathrm{~h}$ /day) of restraint stress in mice increases anxiogenic behaviors [41-43]. In rats, studies have demonstrated that restraint for 21 days ( $6 \mathrm{~h} /$ day) or 14 days ( $1 \mathrm{~h} /$ day) was sufficient to decrease open arm entries $[44,45]$. Thus, the anxiogenic-like behavior exhibited by stressed mice suggests that our 14 day restraint stress protocol is effective in inducing anxiety in these animals. However, there have been no reports on the behavior of cagemates of mice subjected to chronic stress.

Previous findings by our laboratory have demonstrated that cohabitation with mice subjected to sciatic nerve constriction for 14 days induces anxiety behaviors in their cagemates assessed by the elevated plus maze test $[6,12]$. Therefore, our data indicate that the stress protocol described in this paper may be suitable for studying stress-induced emotional contagion.

Furthermore, this protocol appears to be effective for studying nociception in mice. Our results indicate that cohabitation with a subject exposed to chronic stress leads both animals to experience hypernociception in the writhing test. These findings corroborate evidences from previous work that has demonstrated the social modulation of the pain response [46]. Moreover, we expanded on previous findings from our laboratory, showing an increase in the number of writhes in animals directly subjected to stress and observers. Baptista-de-Souza and colleagues [6] observed hypernociception in the cagemates of mice with chronic neuropathic pain. It is important to emphasize that before sciatic nerve constriction, mice were housed together for 14 days to establish familiarity $[6,13]$. In line with the study by Langford et al. [46] that showed shared hypernociception after 28 days of cohabitation and the protocol used by Baptista-de-Souza et al. [6] and Zaniboni et al. [13], our study adds evidence that development of social bounds prior to the initiation of chronic aversive stimulus is an important factor to induce emotional contagion.

According to these studies, it is highly important that tested animals be in the presence of a conspecific also submitted pain $[6,13,46]$. However, we observed hypernociception in both stressed mice and their cagemates even when they were tested alone. In spite of only one animal per cage being exposed to direct stress, the behavioral responses of the cagemate group suggest that cohabitation with a chronically stressed mouse can be considered a social stressor. Thus, our results are in line with findings from studies that have shown increases in pain sensitivity of rodents submitted to chronic restraint and social stress $[18,47,48]$. The difference in hypernociception could be explained by the intensity of the stressor (stressed vs. cagemate), as proposed by Tramullas et al. [48].

Our work also showed that cagemates as well as stressed mice exhibited alterations in defensive behavior. The rat exposure test is an unconditioned aversive stimulus capable of inducing a set of intense physiological and behavioral fear/anxiety responses, such as reduced exploration, increased risk assessment and defensive avoidance [19-22]. Chronic restraint stress was not able to modify total freezing and protected freezing, indicating no difference in fear-related responses in any group. Furthermore, stressed mice and their cagemates, showed significant alterations in defensive behavior compared to controls. These animals exhibited enhanced exploration in unprotected areas and decreased activity in protected area, such as time spent in the burrow area and latency of first exit from the protected area. They also demonstrated diminished risk assessment in the protected areas and increased risk assessment in the unprotected areas, seen through stretch attend posture (SAP). Although these data were unexpected based on our results from the elevated plus maze test, it is important to highlight that alteration in defensive responses is not paralleled by alterations in anxiety-related behaviors, suggesting different neural mechanisms involved in the behavioral responses to elevated plus maze and rat exposure tests.

The possible explanation for the different expression of anxiety behaviors in both tests may be due to the structure of each model. Previous research has indicated that rodents may present different defensive responses to different stressors with varying intensities and distances [20]. Since mice in the rat exposure test are in the presence of a proximal predator, this data suggest that stressed mice and their cagemates are looking for an escape route from the threat [20]. Although these arguments are purely speculative, the rat exposure test data contribute to the suggestion that the protocol described in this work is suitable for the evaluation of the effects of repeated stress on defensive responses. In this regard, more studies are needed to elucidate how chronic stress affects behavior in the rat exposure test.

In conclusion, the findings of this study, along with previous reports from our laboratory, suggest that cagemates of mice subjected to long-lasting aversive situations (stress or sciatic nerve injury) may experience behavioral alterations, such as anxiogeniclike responses and pain hypersensitivity. Furthermore, this is the first study to show the effects of chronic stress on unconditioned defensive responses. The alterations in defensive behavior demonstrated by the rat exposure test as well as observations from the elevated plus maze and writhing tests after prolonged stress, 
support the validity of our protocol for the investigation of stressinduced emotional contagion in mice.

\section{Acknowledgements}

Carneiro de Oliveira, P.E. was recipient of CAPES-PNPD research fellowship (2639/2011); Zaniboni, C.R. was recipient of CAPES and FAPESP research fellowship (2015/11908-9); Carmona, I.M. was recipient of CNPq research fellowship (376979/2014-3); Canto-de-Souza, A. was recipient of CNPq research fellowships (482356/2013-8 and 309201/2015-2). The authors would like to thank Lara Maria Silveira for her technical assistance.

\section{References}

[1] R. Plutchik, Evolutionary bases of empathy, in: N. Eisenberg, J. Strayer (Eds.), Empathy and its development, Cambridge University Press, London, 1987, pp. 38-46.

[2] C. Gonzalez-Liencres, G. Juckel, C. Tas, A. Friebe, M. Brüne, Emotional contagion in mice: the role of familiarity, Behav. Brain Res. 263 (2014) 16-21.

[3] J.B. Panksepp, G.P. Lahvis, Rodent empathy and affective neuroscience, Neurosci. Biobehav. Rev. 35 (2011) 1864-1875.

[4] M. Kavaliers, E. Choleris, Antipredator responses and defensive behavior: ecological and ethological approaches for the neurosciences, Neurosci. Biobehav. Rev. 25 (2001) 577-586.

[5] I. Yalcin, F. Barthas, M. Barrot, Emotional consequences of neuropathic pain: insight from preclinical studies, Neurosci. Biobehav. Rev. 47 (2014) 154-164

[6] D. Baptista-de-Souza, A.C. Nunciato, B.C. Pereira, G. Fachinni, C.R. Zaniboni, A. Canto-de-Souza, Mice undergoing neuropathic pain induce anxiogenic-like effects and hypernociception in cagemates, Behav. Pharmacol. 26 (2015) 664-672.

[7] K. Roeska, A. Ceci, R.D. Treede, H. Doods, Effect of high trait anxiety on mechanical hypersensitivity in male rats, Neurosci. Lett. 464 (2009) 160-164.

[8] S. Çivi, G. Emmez, A.V. Dere, O.A. Börcek, H. Emmez, Effects of quercetin on chronic constriction nerve injury in na experimental rat model, Acta Neurochir. (Wien) 158 (2016) 959-965.

[9] M. Benbouzid, V. Pallage, M. Rajalu, E. Waltisperger, S. Doridot, P. Poisbeau, M.J. Freund-Mercier, M. Barrot, Sciatic nerve cuffing in mice: a model of sustained neuropathic pain, Eur. J. Pain 12 (2008) 591-599.

[10] I. Decosterd, C.J. Woolf, Spared nerve injury: an animal model of persistent peripheral neuropathic pain, Pain 87 (2000) 149-158.

[11] K.I. Vadakkan, Y.H. Jia, M.A. Zhuo, A behavioral model of neuropathic pain induced by ligation of the common peroneal nerve in mice, J. Pain 6 (2005) 747-756.

[12] I.M. Carmona, D. Baptista-de-Souza, A. Canto-de-souza, Anxiogenic-like behaviors induced by living with a conspecific in neuropathic pai condition are attenuated by systemic injection of midazolam in mice, J. Pain 17 (2016) S58-S59.

[13] C.R. Zaniboni, D. Baptista-de-Souza, A. Canto-de-Souza, Effects of midazolam on hypernociception induced by living with a conspecific in neuropathic pain condition in mice, J. Pain 17 (2016) S58.

[14] Y.M. Ulrich-Lai, W. Xie, J.T. Meij, C.M. Dolgas, L. Yu, J.P. Herman, Limbic and HPA axis function in an animal model of chronic neuropathic pain, Physiol. Behav. 88 (2006) 67-76.

[15] E. Vachon-Presseau, M. Roy, M.O. Martel, E. Caron, M.F. Marin, J. Chen, G. Albouy, I. Plante, M.J. Sullivan, S.J. Lupien, P. Rainville, The stress model of chronic pain: evidence from basal cortisol and hippocampal structure and function in humans, Brain 136 (2013) 815-827.

[16] S. Chiba, T. Numakawa, M. Ninomiya, M.C. Richards, C. Wakabayashi, H. Kunugi, Chronic restraint stress causes anxiety- and depression-like behaviors downregulates glucocorticoid receptor expression, and attenuates glutamate release induced by brain-derived neurotrophic factor in the prefrontal cortex, Prog. Neuropsychopharmacol. Biol. Psychiatry 39 (2012) 112-119.

[17] L. Crema, M. Schlabitz, B. Tagliari, A. Cunha, F. Simão, R. Krolow, L. Pettenuzzo, C. Salbego, D. Vendite, A.T. Wyse, C. Dalmaz, K+ Na+ ATPase activity is reduced in amygdala of rats with chronic stress-induced anxiety-like behavior, Neurochem. Res. 35 (2010) 1787-1795.

[18] G.H. Gameiro, P.H. Gameiro, S. Andrade Ada, L.F. Pereira, M.T. Arthuri, F.K. Marcondes, M.C. Veiga, Nociception- and anxiety-like behavior in rats submitted to different periods of restraint stress, Physiol. Behav. 87 (2006) 643-649.

[19] R.J. Blanchard, M.A. Hebert, P. Ferrari, P. Palanza, R. Figueira, D.C. Blanchard, S. Parmigiani, Defensive behaviors in wild and laboratory (Swiss) mice: the mouse defense test battery, Physiol. Behav. 65 (1998) 201-209.

[20] M. Yang, H. Augustsson, C.M. Markham, D.T. Hubbard, D. Webster, P.M. Wall, R.J. Blanchard, D.C. Blanchard, The rat exposure test: a model of mouse defensive behaviors, Physiol. Behav. 81 (2004) 465-473.

[21] V.C. Amaral, K. Santos Gomes, R.L. Nunes-de-Souza, Increased corticosterone levels in mice subjected to the rat exposure test, Horm. Behav. 57 (2010) $128-133$.
[22] K.F. Campos, V.C. Amaral, J.L. Rico, T.T. Miguel, R.L. Nunes-de-Souza, Ethopharmacological evaluation of the rat exposure test: a prey-predator interaction test, Behav. Brain Res. 240 (2013) 160-170.

[23] R. Fuertig, D. Azzinnari, G. Bergamini, F. Cathomas, H. Sigrist, E. Seifritz, S. Vavassori, A. Luippold, B. Hengerer, A. Ceci, C.R. Pryce, Mouse chronic social stress increases blood and brain kynurenine pathway activity and fear behaviour: both effects are reversed by inhibition of indoleamine 2,3-dioxygenase, Brain Behav. Immun. 54 (2016) 59-72.

[24] M.K. Green, C.S. Rani, A. Joshi, A.E. Soto-Piña, P.A. Martinez, A. Frazer, R. Strong, D.A. Morilak, Prenatal stress induces long term stress vulnerability, compromising stress response systems in the brain and impairing extinction of conditioned fear after adult stress, Neuroscience 192 (2011) 438-451.

[25] C.A. Wilson, A. Vazdarjanova, A.V. Terry Jr., Exposure to variable prenatal stress in rats: effects on anxiety-related behaviors, innate and contextual fear, and fear extinction, Behav. Brain Res. 238 (2013) 279-288.

[26] R.G. Lister, The use of a plus-maze to measure anxiety in the mouse Psychopharmacology (Berl.) 92 (1987) 180-185.

[27] R.J. Rodgers, N.J. Johnson, Factor analysis of spatiotemporal and ethological measures in the murine elevated plus-maze test of anxiety, Pharmacol. Biochem. Behav. 52 (1995) 297-303.

[28] R.J. Rodgers, A. Dalvi, Anxiety, defense and the elevated plus-maze, Neurosci. Biobehav. Rev. 21 (1997) 801-810.

[29] H.O. Collier, L.C. Dinneen, C.A. Johnson, C. Schneider, The abdominal constriction response and its suppression by analgesic drugs in the mouse, $\mathrm{Br}$. J. Pharmacol. Chemother. 32 (1968) 295-310.

[30] J.M. Hall, A.R. Witter, R.R. Racine, R.E. Berg, A. Podawiltz, H. Jones, M.E. Mummert, Chronic psychological stress suppresses contact hypersensitivity: potential roles of dysregulated cell trafficking and decreased IFN- $\gamma$ production, Brain Behav. Immun. 36 (2014) 156-164

[31] N. Liu, L.H. Wang, L.L. Guo, G.Q. Wang, X.P. Zhou, Y. Jiang, J. Shang, K. Murao, J.W. Chen, W.Q. Fu, G.X. Zhang, Chronic restraint stress inhibits hair growth via substance P mediated by reactive oxygen species in mice, PLoS One 8 (2013) e61574.

[32] C. Mo, T. Renoir, A.J. Hannan, Effects of chronic stress on the onset and progression of Huntington's disease in transgenic mice, Neurobiol. Dis. 71 (2014) 81-94.

[33] F.C. Cruz, M.T. Marin, R.M. Leão, C.S. Planeta, Behavioral and neuroendocrine effects of the exposure to chronic restraint or variable stress in early adolescent rats, Int. J. Dev. Neurosci. 30 (2012) 19-23.

[34] L. Wang, L.L. Guo, L.H. Wang, G.X. Zhang, J. Shang, K. Murao, D.F. Chen, X.H. Fan, W.Q. Fu, Oxidative stress and substance P mediate psychological stress-induced autophagy and delay of hair growth in mice, Arch. Dermatol. Res. 307 (2015) 171-181.

[35] M.T. Marin, F.C. Cruz, C.S. Planeta, Chronic restraint or variable stresses differently affect the behavior, corticosterone secretion and body weight in rats, Physiol. Behav. 90 (2007) 29-35

[36] S. Zhu, J. Wang, Y. Zhang, V. Li, J. Kong, J. He, X.M. Li, Unpredictable chronic mild stress induces anxiety and depression-like behaviors and inactivates AMP-activated protein kinase in mice, Brain Res. 1576 (2014) 81-90.

[37] L. Bardin, N. Malfetes, A. Newman-Tancredi, R. Depoortère, Chronic restraint stress induces mechanical and cold allodynia, and enhances inflammatory pain in rat: relevance to human stress-associated painful pathologies, Behav. Brain Res. 205 (2009) 360-366.

[38] A. Costa, A. Smeraldi, C. Tassorelli, R. Greco, G. Nappi, Effects of acute and chronic restraint stress on nitroglycerin-induced hyperalgesia in rats, Neurosci. Lett. 383 (2005) 7-11.

[39] G.D. Gamaro, M.H. Xavier, J.D. Denardin, J.A. Pilger, D.R. Ely, M.B. Ferreira, C. Dalmaz, The effects of acute and repeated restraint stress on the nociceptive response in rats, Physiol. Behav. 63 (1998) 693-697.

[40] I.L. da Silva Torres, S.N. Cucco, M. Bassani, M.S. Duarte, P.P. Silveira, A.P. Vasconcellos, A.S. Tabajara, G. Dantas, F.U. Fontella, C. Dalmaz, M.B. Ferreira, Long-lasting delayed hyperalgesia after chronic restraint stress in rats-effect of morphine administration, Neurosci. Res. 45 (2003) 277-283.

[41] M.H. Kim, Y.H. Leem, Chronic exercise improves repeated restraint stress-induced anxiety and depression through 5HT1A receptor and cAMP signaling in hippocampus, J. Exerc. Nutr. Biochem. 18 (2014) 97-104.

[42] Y.H. Leem, S. Oh, 3,4,5-Trimethoxycinnamin acid ameliorates restraint stress-induced anxiety and depression, Neurosci. Lett. 585 (2015) 54-59.

[43] H.J. Park, H.S. Shim, H. Kim, K.S. Kim, H. Lee, D.H. Hahm, I. Shim, Effects of Glycyrrhizae Radix on repeated restraint stress-induced neurochemical and behavioral responses, Korean J. Physiol. Pharmacol. 14 (2010) 371-376.

[44] M.N. Hill, C.J. Hillard, B.S. McEwen, Alterations in corticolimbic dendritic morphology and emotional behavior in cannabinoid CB1 receptor-deficient mice parallel the effects of chronic stress, Cereb. Cortex 21 (2011) 2056-2064.

[45] H. Shoji, K. Mizoguchi, Acute and repeated stress differentially regulates behavioral endocrine, neural parameters relevant to emotional and stress response in young and aged rats, Behav. Brain Res. 211 (2010) 169-177.

[46] D.J. Langford, S.E. Crager, Z. Shehzad, S.B. Smith, S.G. Sotocinal, J.S. Levenstadt, M.L. Chanda, D.J. Levitin, J.S. Mogil, Social modulation of pain as evidence for empathy in mice, Science 312 (2006) 1967-1970.

[47] S.V. Coutinho, P.M. Plotsky, M. Sablad, J.C. Miller, H. Zhou, A.L. Bayati, J.A. McRoberts, E.A. Mayer, Neonatal maternal separation alters stress-induced responses to viscerosomatic nociceptive stimuli in rat, Am. J. Physiol. Gastrointest. Liver Physiol. 282 (2002) 307-316.

[48] M. Tramullas, T.G. Dinan, J.F. Cryan, Chronic psychosocial stress induces visceral hyperalgesia in mice, Stress 15 (2012) 281-292. 